\title{
Price and Quality Competition*
}

\author{
Ioana Chioveanu ${ }^{\dagger}$ \\ University College London
}

February 2010

\begin{abstract}
This study considers an oligopoly model with simultaneous price and quality choice. Exante homogeneous sellers compete by offering products at one of two quality levels. The consumers have heterogeneous tastes for quality: for some consumers it is efficient to buy a high quality product, while for others it is efficient to buy a low quality product. In the symmetric equilibrium firms use mixed strategies that randomize both price and quality, and obtain strictly positive profits. This framework highlights trade-offs which determine the impact of consumer protection policy in the form of quality standards.
\end{abstract}

Keywords: Oligopoly; Price and quality competition; Quality standards JEL classification: L13; L15; L50

\section{Introduction}

Differences in the quality of groceries or household supplies sometimes stem from packaging or labelling, availability of information, or expert/celebrity endorsements. Some products indicate an improved recipe, added vitamin C, are labelled as healthy living options, or are endorsed by celebrities/experts. Such quality improvements most often do not call for a long term decision. Firms can relatively frequently change the packaging, slightly improve a recipe or arrange for an endorsement, and rivals are unlikely to observe the internal price-quality decision before making their own choices. Furthermore, in these markets consumers are likely to differ in their willingness to pay for quality. Building on these observations, this study proposes an oligopoly model where sellers simultaneously compete in quality and price.

More specifically, this analysis shows that in the symmetric equilibrium of the price-quality competition model, the firms randomize on both prices and qualities. In this setting, price and quality dispersion emerges from competition of ex-ante identical sellers in the provision of a homogeneous product. Some important features of this model are the following. Sellers can choose between two levels of quality. All consumers value both qualities, but it is efficient for

${ }^{*}$ I am grateful to Ugur Akgun, Mark Armstrong, V. Bhaskar, Steffen Huck, and Jidong Zhou for useful comments.

${ }^{\dagger}$ Department of Economics and ELSE, UCL, Gower Street, London WC1E 6BT, UK, Email: i.chioveanu@ucl.ac.uk. 
some consumers to buy a high-quality, and for others to buy a low-quality. ${ }^{1}$ The sellers know the valuations for either quality and their distribution in the population, but they cannot distinguish among buyers and, therefore, cannot price discriminate. The sellers offer their products at only one of two quality levels. ${ }^{2}$

In some professional service markets, the providers (e.g., lawyers, consultants, architects) also compete for consumers not only by quoting a price for the service, but also by simultaneously setting a quality level. The firms are able to provide the same service at different levels of quality, but often a firm's offer is not preceded by a negotiation process, so that there is little transparency regarding the alternative qualities that could have been provided (and could have been closer to consumer's actual needs.) For instance, when economic consulting firms make a pitch to a customer, they simply submit a price-quality bid without knowing with certainty the exact level of complexity preferred for the project. A firm seeking professional advice might have a higher or a smaller stake in an ongoing antitrust investigation, and a person seeking legal advice might have a higher or a lower income. Another example of markets where the firms compete simultaneously over price and quality is the business software one. In this case, a quality level might stem, for instance, from the maintenance service terms. In these markets, corporate customers are likely to value the speed of response more than home users.

In the price-quality competition model, low-quality is always associated with lower prices, and high-quality with higher prices. At equilibrium, there is a positive probability that any one firm is the sole provider of a given quality and, even though it faces some competition from the other quality, it can charge a price in excess of marginal cost. The difference between the highest (lowest) price for a high-quality product and lowest (highest) price for a low-quality product is equal to the difference in high-end (low-end) consumers' valuation for the high and low-quality products. Moreover, the symmetric equilibrium leads to positive expected profits for the firms.

Due to the fact that high-end (low-end) consumers can eventually shift to a different quality, the highest price at which a high-quality (low-quality) is offered is strictly lower than high-end (low-end) consumers' valuation of the high-quality (low-quality). Low-end consumers obtain a positive net surplus if they purchase a low-quality and, for a nontrivial range of parameters, this is also the case when they buy a high-quality. High-end consumers are left with a positive net surplus regardless of the quality they consume. This contrasts with most price dispersion models where prices equal to consumers' willingness to pay for the good are charged with positive probability. ${ }^{3}$ This is the case in Varian (1980) and Rosenthal (1980), for instance, where homogeneous sellers compete for consumers with identical preferences who differ in their search costs. Some buyers have infinite search costs and shop at random, while the others purchase from the lowest price seller. The expected profit of a firm equals the monopoly profit on its locked-in group (i.e., the corresponding share of random shoppers.)

\footnotetext{
${ }^{1}$ That is, high-end consumers' marginal valuation of the high quality exceeds its cost, while the remaining (low-end) consumers' marginal valuation of the high quality does not exceed its cost.

${ }^{2}$ However, the equilibrium characterized in this research is consistent with a market in which the sellers first decide whether to offer only one or both qualities, but to put up a menu of qualities they incur a positive cost.

${ }^{3}$ For a review of the price dispersion literature see Baye, Morgan and Scholten (2006).
} 
Armstrong and Chen (2009) analyze price and quality competition in oligopoly. In their model, like in the current one, a high-quality is associated with high prices and a low-quality with lower prices. However, they consider consumers with homogeneous tastes for quality who differ in their attentiveness to quality (a low-quality is worthless and would not be produced if there were no inattentiveness). ${ }^{4}$

Other models of price and quality competition consider consumer heterogeneity, but focus on perfectly competitive markets. Wolinsky (1983) analyses a market where the consumers may differ in their taste for quality and receive noisy signals of a seller's quality. He shows that a separating equilibrium where prices fully reveal quality exists under certain conditions. Buyers with homogenous tastes for quality might still differ in their knowledge of product quality: while some are fully aware of quality, others are not. ${ }^{5}$ Along this line, Cooper and Ross (1984) allow quality-uninformed consumers to have rational expectations about the price-quality relationship. They show that, with U-shaped average cost functions, there exists a rational expectations equilibrium with dispersion in qualities but not in prices.

Most oligopoly models of price and quality competition focus on cases where quality is a long-run variable, while prices can be adjusted in the short-run (see Shaked and Sutton, 1982 for a seminal contribution). They reflect the fact that a quality improvement might involve observable changes in the production facility or long-run investments (e.g., R\&D). While this is often the case, there are also many markets where a quality update does not call for significant investments or is unlikely to be observed by the rivals prior to price competition. In the latter cases, strategic interaction is better captured by simultaneous price-quality competition.

The price-quality competition model offers a framework for the analysis of quality standards (QS) in oligopoly. Such intervention has been employed in professional service provision either by governmental entities or professional associations to improve market performance. ${ }^{6}$ However, QS in oligopoly markets received little attention in the economic literature, and the extant analyses focus on instances in which quality choices precede pricing decisions. The impact of QS in this framework is driven by the trade-off between increasing competition and offering consumers the quality they desire, and it pins down the potentially perverse effects of quality regulation. The impact of a relevant QS which would lead to Bertrand competition depends on the underlying market conditions. This study shows that the a QS might reduce both total welfare and consumer surplus. However, depending on the parameter values, a QS might also boost both total welfare and consumer surplus, or harm welfare while benefiting the consumers.

The paper is organized as follows. Section 2 presents the model and the symmetric mixed strategy equilibrium when the market is fully covered. Section 3 discusses quality standards and section 4 concludes. The proofs missing from the text and the characterization of the symmetric equilibrium when the market is not covered are relegated to the Appendix.

\footnotetext{
${ }^{4}$ An alternative "rational" interpretation of their model is that some consumers do not mind consuming the low-quality product.

${ }^{5}$ Yet another type of consumer heterogeneity is present in Besancenot and Vranceanu (2004), where high-end consumers are loyal to the high-quality product (they only care for the extra features provided by a high-quality).

${ }^{6}$ See, for instance, OFT (2001) and EC (2004, 2005) reports on competition in professions.
} 


\section{$2 \quad$ A Model of Price and Quality Competition}

\section{- The Framework}

Consider a market where $N \geq 2$ identical suppliers can offer an otherwise homogeneous product at two quality levels, a high one $\left(q_{H}\right)$ and a low one $\left(q_{L}\right)$. The constant marginal cost of producing the high-quality is $c>0$, while the one of producing the low-quality is normalized to zero. Sellers simultaneously choose prices and qualities. Each firm offers only one quality level. There is a unit mass of consumers, each demanding one unit of the product. A fraction $1-\alpha$ of the consumers are willing to pay $\theta_{1}$ for the low-quality and $\theta_{3}$ for the high-quality, while a fraction $\alpha$ of the consumers has willingness to pay for the low and high-quality equal to $\theta_{2}$ and $\theta_{4}$, respectively. I assume that $\theta_{1}>0, \theta_{3}>c$ and $\theta_{i}>\theta_{j}$ for $i>j$, and refer to the consumers with a lower (higher) valuation for either quality as "low-end" ("high-end"). ${ }^{7}$ Assume that it is efficient for low-end consumers to buy a low-quality and for the high-end consumers to buy a high-quality product, that is $\theta_{3}-\theta_{1}<c<\theta_{4}-\theta_{2}$. However, at equilibrium consumers will purchase the quality which provides the best deal.

In this model, consumers are able to compare all available products both in terms of price and quality before they purchase. Firms know consumers' valuations for either quality and the market composition, but cannot price discriminate. When $\alpha=0$ (or $\alpha=1$ ), firms supply the efficient quality $q_{L}$ (or $q_{H}$ ), compete a la Bertrand, and make zero profits. The remainder of this paper focuses on $\alpha \in(0,1)$.

Lemma 1 For $\alpha \in(0,1)$, a) there is no symmetric pure strategy equilibrium; and b) for $N \geq 4$, there is a family of asymmetric pure strategy equilibria, where at least two firms choose each quality, low-quality is offered at $p=0$ and high-quality at $p=c$, and all firms make zero profits. Total welfare and consumer surplus are given by

$$
\left(\theta_{4}-c\right) \alpha+\theta_{1}(1-\alpha)
$$

Armstrong and Chen (2009) present similar results in a model of bounded rationality (inattentiveness) with price-quality competition. In their setting, consumers have homogeneous tastes for quality, but a fraction of them do not observe (or assess) quality and (wrongly) believe that all products are of the same (high) quality. ${ }^{8}$ In the symmetric equilibrium of their model firms mix on both qualities and prices. To exploit consumers' inattentiveness, firms provide a useless low-quality product with a positive probability. In contrast, in the current model firms face fully rational consumers and the symmetric mixed strategy equilibrium discussed below is related to heterogeneity in consumers' tastes.

\section{- The Symmetric Mixed-Strategy Equilibrium}

For any $N \geq 2$, there exists a symmetric equilibrium in which firms choose both prices and qualities stochastically and make positive profits. The convex hull of the range of prices which

\footnotetext{
${ }^{7}$ Note that consumers' valuations can be derived from Mussa-Rosen preferences.

${ }^{8}$ Consumers' valuations in their model are not consistent with Mussa-Rosen preferences.
} 
are assigned positive probability is $\left[p_{0}, p_{4}\right]$, with $0<p_{0}<p_{4}<\theta_{4}$. There are two threshold prices $p_{1} \in\left[p_{0}, \theta_{1}\right]$ and $p_{2} \in\left[c, p_{4}\right]$ such that a low-quality product is chosen if $p \leq p_{1}$ and a high one if $p \geq p_{2}>p_{1}$. The probability of offering a low-quality product is $F\left(p_{1}\right)=F\left(p_{2}\right)=P$. The discussion in this section focuses on a situation in which the market is fully covered in equilibrium. Appendix A presents a necessary condition for the market to be fully covered for an arbitrary number of firms. However, for expositional simplicity, this section assumes that the following sufficient condition holds:

$$
\alpha \leq \frac{\theta_{2}+\theta_{3}-\theta_{4}}{\theta_{3}-c}
$$

This condition guarantees that $p_{4} \leq \theta_{3}$ so that regardless of the price draw all consumers buy the product. A necessary condition for (2) to hold is $\theta_{3}>\theta_{4}-\theta_{2}$. Finally, note that if $\theta_{3} \leq \theta_{4}-\theta_{2}$, then $p_{4}>\theta_{3}$ and with a positive probability low-end consumers are excluded from the market. The analysis of this case is presented in Appendix B.

When (2) holds, the support of the equilibrium price distributions is $S=\left[p_{0}, p_{1}\right] \cup\left[p_{2}, p_{4}\right]^{9}{ }^{9}$ The boundary prices $p_{2}$ and $p_{4}$ satisfy:

$$
p_{2}=p_{1}+\theta_{3}-\theta_{1} \text { and } p_{4}=p_{0}+\theta_{4}-\theta_{2} .
$$

The difference between the lowest price at which a high-quality is offered $\left(p_{2}\right)$ and the highest price at which the low-quality is offered $\left(p_{1}\right)$ is exactly equal to low-end consumers' marginal valuation for quality (that is, the difference between low-end consumers' valuation for the highquality and their valuation for the low-quality, $\theta_{3}-\theta_{1}$ ). At the same time, the difference between the highest price at which a high-quality is offered $\left(p_{4}\right)$ and the lowest price at which the lowquality product is offered $\left(p_{0}\right)$ is determined by high-end consumers' marginal valuation for quality (that is, the difference between high-end consumers' valuation for the high-quality and their valuation for the low-quality product, $\theta_{4}-\theta_{2}$ ).

Then, notice that the expected profits of a firm at price $p_{0}$ are

$$
\pi\left(p_{0}\right)=p_{0}\left[1-\alpha+\alpha\left(P+1-F\left(p_{0}+\theta_{4}-\theta_{2}\right)\right)^{N-1}\right]=p_{0}\left[1-\alpha+\alpha P^{N-1}\right] .
$$

At this price only a low-quality is offered. Low-end consumers buy for sure at price $p_{0}$ : a lowquality is never sold at a lower price, and a high-quality (for which they are willing to pay at most $\left.\theta_{3}\right)$ provides them with a lower surplus even when it is sold at its lowest possible price $\left(p_{2}\right)$. High-end consumers buy at $p_{0}$ only if all firms supply a low-quality. Notice that even if the high-quality is provided at its maximal price $\left(p_{4}\right)$ still high-end consumers are indifferent between purchasing the high-quality and buying a low-quality at $p_{0}$, its lowest possible price (this happens because $\theta_{2}-p_{0}=\theta_{4}-p_{4}$ ). The last equality in expression (4) follows from the fact that $F\left(p_{0}+\theta_{4}-\theta_{2}\right)=F\left(p_{4}\right)=1$. This must be the case because if all firms had an atom at $p_{4}$, then an individual firm would be strictly better off moving mass to $p_{4}-\epsilon$ for some small

\footnotetext{
${ }^{9}$ When the market is covered in the symmetric equilibrium, the only relevant boundary prices are $p_{0}, p_{1}, p_{2}$ and $p_{4}$. In the uncovered market analysis, boundary price $p_{3}$ comes into play (see Appendix B).
} 
$\epsilon>0 .{ }^{10}$ The expected profits at price $p_{4}$ are given by

$$
\pi\left(p_{4}\right)=p_{4} \alpha P^{N-1}=\left(p_{0}+\theta_{4}-\theta_{2}-c\right) \alpha P^{N-1} .
$$

At price $p_{4}$ only a high-quality is offered. When $p_{4} \leq \theta_{3}$, low-end consumers would buy at $p_{4}$ with probability $\left(1-F\left(p_{4}\right)\right)^{N-1}$. This is the probability that all suppliers price above $p_{4}$ and is equal to zero.

In the symmetric mixed strategy equilibrium, a firm is indifferent between any two prices which are assigned positive density. Then, from the equilibrium requirement that $\pi\left(p_{0}\right)=\pi\left(p_{4}\right)$, it follows that

$$
p_{0}=\left(\theta_{4}-\theta_{2}-c\right) \frac{\alpha}{1-\alpha} P^{N-1} .
$$

Note that low-end consumers are indifferent between buying a low-quality at price $p_{1}$ and a high-quality at price $p_{2}$ (see (3)). In effect, they weakly prefer a low-quality at price $p \leq p_{1}$ to a high-quality. High-end consumers buy a low-quality at price $p_{1}$ only if no firm supplies a high-quality and all low-quality suppliers price above $p_{1}$. But, this happens with probability zero. Formally, the expected profit of a firm charging price $p_{1}$ is:

$$
\pi\left(p_{1}\right)=p_{1}\left[(1-\alpha)\left(1-F\left(p_{1}\right)\right)^{N-1}+\alpha\left(P-F\left(p_{1}\right)\right)^{N-1}\right]=p_{1}(1-\alpha)(1-P)^{N-1} .
$$

By the previous argument low-end consumers buy at $p_{2}$ only if no firm supplies a low-quality. High-end consumers buy for sure at price $p_{2}$ : this is the best high-quality deal they can get and it provides a higher net surplus than the best possible low-quality deal $\left(\theta_{2}-p_{0}<\theta_{4}-\left(p_{1}+\theta_{3}-\theta_{1}\right) \Leftrightarrow\right.$ $\left.p_{2}<p_{4}\right)$. Then, the expected profit of a firm at price $p_{2}$ is:

$$
\pi\left(p_{2}\right)=\left(p_{2}-c\right)\left[\alpha+(1-\alpha)\left(1-F\left(p_{2}\right)\right)^{N-1}\right]=\left(p_{1}+\theta_{3}-\theta_{1}-c\right)\left[\alpha+(1-\alpha)(1-P)^{N-1}\right] .
$$

The constant profit condition $\pi\left(p_{1}\right)=\pi\left(p_{2}\right)$ defines

$$
p_{1}=\left(\theta_{1}-\theta_{3}+c\right)\left[1+\frac{1-\alpha}{\alpha}(1-P)^{N-1}\right] .
$$

Using (6), (8), and the equilibrium requirement that $\pi\left(p_{0}\right)=\pi\left(p_{2}\right)$, I obtain

$$
\left(\frac{1-\alpha}{\alpha}\right)^{2} \frac{\theta_{1}-\theta_{3}+c}{\theta_{4}-\theta_{2}-c}\left[\frac{\alpha+(1-\alpha)(1-P)^{N-1}}{(1-\alpha)+\alpha P^{N-1}}\right]=\left(\frac{P}{1-P}\right)^{N-1}
$$

Expression (9) implicitly defines the probability of choosing a low-quality $(P)$ which is well defined. ${ }^{11}$ If (2) holds, these expressions are sufficient to characterize the equilibrium strategies.

Proposition 1 If (2) holds and $N \geq 2$, there exists a symmetric mixed strategy equilibrium where firms randomize on prices and qualities. Firms choose prices with support $S=\left[p_{0}, p_{1}\right] \cup$ $\left[p_{2}, p_{4}\right]$. The boundary prices $p_{0}, p_{1}, p_{2}$ and $p_{4}$ are defined by (3), (6) and (8). The atomless price cdf $F(p)$ is defined implicitly by

$$
\begin{gathered}
p\left[(1-\alpha)(1-F(p))^{N-1}+\alpha(P-F(p))^{N-1}\right]=p_{1}(1-\alpha)(1-P)^{N-1} \text { for } p_{0} \leq p \leq p_{1} \text { and } \\
(p-c)\left[\alpha(P+1-F(p))^{N-1}+(1-\alpha)(1-F(p))^{N-1}\right]=\left(p_{4}-c\right) \alpha P^{N-1} \text { for } p_{2} \leq p \leq p_{4}
\end{gathered}
$$

\footnotetext{
${ }^{10}$ This would result in a jump up in demand and only a negligible loss due to the lower price.

${ }^{11}$ The RHS of (9) is increasing in $P$ and ranges from 0 to $\infty$, while the LHS is positive and decreasing in $P$, such that there is unique solution in $[0,1]$.
} 
where $P=F\left(p_{1}\right)=F\left(p_{2}\right)$ is the probability of choosing a low-quality and is defined by (9). A low-quality product is associated with prices in $\left[p_{0}, p_{1}\right]$ and a high-quality product with prices in $\left[p_{2}, p_{4}\right]$.

In this symmetric mixed strategy equilibrium, firms offer both a low-quality (at a relatively low price) and a high-quality (at a higher price) with positive probability. As a result of this randomization, with a positive probability, each firm is the sole provider of a given quality and the sellers are able to sustain positive profits. The mixed strategy equilibrium crucially depends on demand heterogeneity: for some consumers it is efficient to buy a low-quality, while for others it is efficient to buy a high-quality. ${ }^{12}$

Recall that each firm chooses only one quality level in this model. Even if firms could offer a menu of (both) qualities at a cost, the equilibrium presented in Proposition 1 would still apply to a game in which firms first decide if to provide just one quality level or both. If firms offered both qualities at different prices, they would end up competing a la Bertrand in two separate markets. Then, they would obtain zero profits and be unable to cover the cost of providing both qualities. Similarly, if firms face some fixed costs of entry, only the mixed strategy equilibrium could support entry.

In the covered market equilibrium presented in Proposition 1, high-end consumers buy a high-quality product if at least one firm supplies it (which happens with probability $1-P^{N}$ ) and buy a low-quality product only if all firms offer a low-quality. Low-end consumers buy a low-quality product if at least one firm supplies it (which happens with probability $1-(1-P)^{N}$ ) and buy a high-quality product only if all firms offer high-quality products. Then, welfare is given by

$$
\left(\theta_{4}-c\right) \alpha\left(1-P^{N}\right)+\theta_{2} \alpha P^{N}+\theta_{1}(1-\alpha)\left[1-(1-P)^{N}\right]+\left(\theta_{3}-c\right)(1-\alpha)(1-P)^{N} .
$$

Aggregate profits follow from (5) and (6). Consumer surplus equals total welfare minus aggregate profits. Algebraic manipulations lead to the following result.

Corollary 1 If (2) holds, at equilibrium, the expected profit of a firm is

$$
\pi_{E}=\left(\theta_{4}-\theta_{2}-c\right)\left(1+\frac{\alpha}{1-\alpha} P^{N-1}\right) \alpha P^{N-1},
$$

total welfare is

$$
\left(\theta_{4}-c\right) \alpha+\theta_{1}(1-\alpha)-\left(\theta_{4}-\theta_{2}-c\right) \alpha P^{N}-\left(c-\theta_{3}+\theta_{1}\right)(1-\alpha)(1-P)^{N},
$$

and consumer surplus is given by

$$
\left(\theta_{4}-c\right) \alpha+\theta_{1}(1-\alpha)-\left(\theta_{4}-\theta_{2}-c\right) \alpha P^{N-1}\left[P+N\left(1+\frac{\alpha}{1-\alpha} P^{N-1}\right)\right]-\left(c-\theta_{3}+\theta_{1}\right)(1-\alpha)(1-P)^{N},
$$

where $P$ is implicitly defined by (9).

\footnotetext{
${ }^{12}$ As expected in a model where consumers can correctly assess product quality, at equilibrium there is a monotonic relationship between price and quality.
} 
The source of welfare and consumer surplus loss in the covered market symmetric equilibrium in Proposition 1 comes from the fact that with a positive probability consumers buy an inefficient quality. With probability one, all consumers buy and obtain a positive net surplus. But, when all firms offer a low-quality (i.e., with probability $P^{N}$ ) high-end consumers obtain a surplus of $\theta_{2}$, lower than the net surplus of $\left(\theta_{4}-c\right)$ which is their first best. Likewise, when all firms offer a high-quality (i.e., with probability $\left.(1-P)^{N}\right)$ low-end consumers buy an inefficiently low-quality. Notice that the first two terms in expressions (12) and (13) give the first best outcome and the last two terms are negative. The term in square brackets in (13) captures the consumer surplus loss due to pricing above marginal cost.

When the market is not covered (that is, for $\left.p_{4}>\theta_{3}\right)^{13}$, the symmetric equilibrium introduces a second source of inefficiency. In that case, low-end consumers are excluded from the market with a positive probability (i.e., $\left(1-F\left(\theta_{3}\right)\right)^{N}>0$ ) and obtain zero surplus. Proposition 3 in Appendix B presents the symmetric equilibrium when the market is not covered. ${ }^{14}$

The following example illustrates the type of mixed strategy equilibrium presented in Proposition $1 .{ }^{15}$

Example 1 Let $N=2, \alpha=.5, \theta_{1}=6, \theta_{2}=8, c=10, \theta_{3}=14$ and $\theta_{4}=20$. Using the results in Proposition 1, at equilibrium, $p_{0}=1, p_{1}=3, p_{2}=11, p_{4}=13$ and $P=.5$. The price $c d f$ is

$$
F(p)=\left\{\begin{array}{c}
.75-\frac{.75}{p} \text { for } p \in[1,3] \\
1.25-\frac{.75}{p-10} \text { for } p \in[11,13]
\end{array} .\right.
$$

Firms offer a low-quality at price $p \in[1,3]$ and offer a high-quality at $p \in[11,13]$. The equilibrium profit is .75. Consumer surplus is 6 and total welfare is 7.5. Figure 1 illustrates the mixed strategy equilibrium in this case.

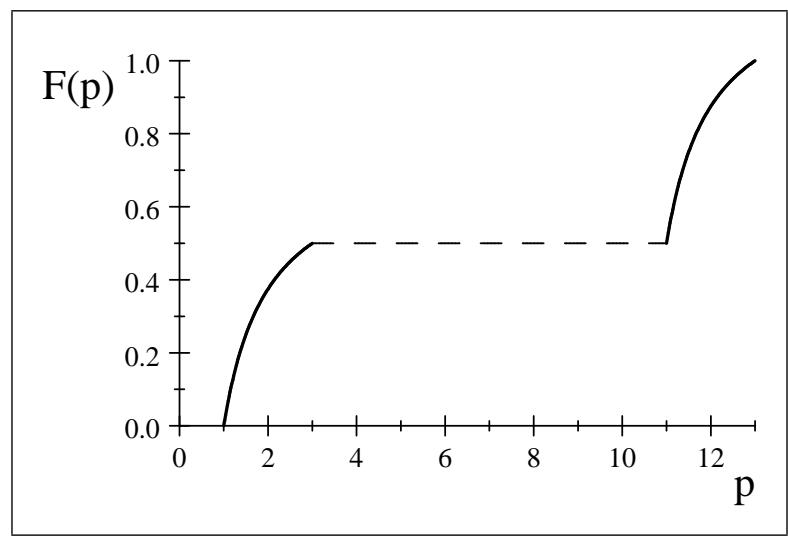

Figure 1: The price cdf in Example 1

\footnotetext{
${ }^{13}$ Recall that a sufficient condition to be in this region is $\theta_{3}<\theta_{4}-\theta_{2}$.

${ }^{14}$ Notice that the type of equilibrium which applies depends both on the degree of consumer heterogeneity and on the number of firms. When $N \rightarrow \infty, p_{0} \rightarrow 0$, and it is possible to have $p_{4}=\theta_{4}-\theta_{2}+p_{0}>\theta_{3}$ for $N<N_{0}$ and $\theta_{4}-\theta_{2}<\theta_{3}$ for $N \geq N_{0}$ for some $N_{0} \geq 3$. For this reason, the necessary condition for an uncovered market symmetric equilibrium to exist depends on $N$. (Appendix A presents a necessary condition for a covered market symmetric equilibrium to exist for an arbitary number of firms.)

${ }^{15}$ Example 2 in Appendix B illustrates the symmetric equilibrium when the market is not fully covered.
} 


\section{- Large Oligopolies}

First notice that when $N \rightarrow \infty$, the probability to choose a low-quality is defined by

$$
\left(\frac{1-\alpha}{\alpha}\right) \frac{\theta_{1}-\theta_{3}+c}{\theta_{4}-\theta_{2}-c}=\left(\frac{P}{1-P}\right)^{N-1} \Leftrightarrow P=\frac{\left[\left(\frac{1-\alpha}{\alpha}\right) \frac{\theta_{1}-\theta_{3}+c}{\theta_{4}-\theta_{2}-c}\right]^{1 / N-1}}{1+\left[\left(\frac{1-\alpha}{\alpha}\right) \frac{\theta_{1}-\theta_{3}+c}{\theta_{4}-\theta_{2}-c}\right]^{1 / N-1}}
$$

Then, $\lim _{N \rightarrow \infty} P=1 / 2$. From (3), (6) and (8), it follows that $p_{0} \rightarrow 0$ and $p_{2} \rightarrow c$ as $N \rightarrow \infty$, such that the equilibrium cdf in Proposition 1 converges to a discrete distribution which assigns probability $1 / 2$ to $p_{0}$ and probability $1 / 2$ to $p_{2}$. In addition, a firm's profit and total industry profits both converge to zero when the market is nearly competitive. The outcome of the symmetric mixed strategy equilibrium converges to the asymmetric pure strategy equilibrium of the game presented in Lemma 1: total welfare and consumer surplus in the limit are equal to $\left(\theta_{4}-c\right) \alpha+\theta_{1}(1-\alpha)($ see $(12)$ and $(13))$.

\section{Consumer Protection Policy: Quality Standards}

The price-quality competition model can be employed to analyze consumer protection policy. This section shows that the impact of a relevant quality standard $(\mathrm{QS})^{16}$, which would lead to Bertrand competition in the symmetric equilibrium, depends crucially on the underlying market conditions. In a setting of imperfect competition and heterogeneity in consumers' preferences for quality, a QS is beneficial for some consumers at the expense of others. Then, the overall effect of such policy on welfare and consumer surplus depends on the composition of the market and on the relative efficiency gain of a quality match.

Studies of QS's in competitive markets with asymmetric information (see Leland, 1979; Shapiro, 1983; and Armstrong, 2008 for a review) have already indicated that some consumer groups might be harmed by the mandatory policy. However, these models do not account for the effects of QS's on prices. Studies of QS's under oligopoly price competition (Ronnen, 1991; Crampes and Hollander, 1995) build on the decrease in prices brought about by the policy and conclude that the intervention is always welfare increasing. ${ }^{17}$ In a duopoly model where firms first choose quality and then prices, and face quality-dependent fixed costs, Ronnen (1991) shows that a QS intensifies price competition by limiting vertical differentiation and is beneficial to consumers. Crampes and Hollander (1995) show, in a related duopoly model where the cost of quality is variable, that a QS might decrease consumer surplus. This happens if the increase in the low-quality brought about by the intervention triggers a significant increase in the highquality. ${ }^{18}$ In this case, the increase in prices due to higher costs offsets the competitive effect. In

\footnotetext{
${ }^{16} \mathrm{~A}$ relevant QS lies between the lowest and the highest available quality levels and has a short-run effect on equilibrium outcomes.

${ }^{17}$ In the case of oligopoly quantity competition, Valletti (2000) shows that QS unambiguously decrease welfare.

${ }^{18}$ In both Ronnen (1991) and Crampes and Hollander (1995), in the unregulated equilibrium, the duopolists choose deterministic asymmetric quality levels. Notice also, that unlike the current model where a QS decreases profits, in these studies the intervention benefits the low-quality supplier and harms the high-quality one.
} 
contrast, in my oligopoly model with exogenous quality levels, the impact of a QS depends on the trade-off between the (positive) competitive effect and the (negative) effect of less product diversity, and overall the intervention might reduce welfare.

Notice that, under a relevant QS, welfare and consumer surplus in the price-quality competition model are both given by

$$
W_{M Q S}=C S_{M Q S}=\alpha\left(\theta_{4}-c\right)+(1-\alpha)\left(\theta_{3}-c\right) .
$$

A straightforward comparison of the welfare levels in the symmetric free-market equilibrium (12) and under a QS (14) leads to the following result.

Proposition 2 If (2) holds and $N \geq 2$, a quality standard is welfare decreasing iff

$$
\left(\theta_{4}-\theta_{2}-c\right) \alpha P^{N}<\left(c-\theta_{3}+\theta_{1}\right)(1-\alpha)\left[1-(1-P)^{N}\right]
$$

and it decreases consumer surplus iff

$$
\left(\theta_{4}-\theta_{2}-c\right) \alpha P^{N-1}\left[P+N\left(1+\frac{\alpha}{1-\alpha} P^{N-1}\right)\right]<\left(c-\theta_{3}+\theta_{1}\right)(1-\alpha)\left[1-(1-P)^{N}\right] .
$$

Notice that, as $N$ goes to infinity, the LHS of both inequalities in Proposition 2 converges to zero while the RHS converges to $\left(c-\theta_{3}+\theta_{1}\right)(1-\alpha)>0$. In nearly competitive markets, a QS harms both consumer surplus and total welfare. The reason is that, in these markets, competition eliminates the price distortion (recall that $p_{0} \rightarrow 0$ and $p_{2} \rightarrow c$ as $N \rightarrow \infty$ ) and the intervention only restricts consumers' choice.

Unlike the limit case, in smaller oligopolies the impact of a QS is not clear-cut. For an arbitrary number of firms, there is no closed-form solution for $P$, the probability to choose a low-quality in the symmetric equilibrium (see (9)). But, for $N=2$, it is possible to calculate $P$ and write the conditions in Proposition 2 in terms of the parameters. This allows to discuss the implication of QS's for different parameter regions.

Corollary 2 Let $N=2$ and $b=\left(\theta_{1}-\theta_{3}+c\right) /\left(\theta_{4}-\theta_{2}-c\right)$. When (2) holds, a) if $\alpha=1 / 2$, then a quality standard is always welfare decreasing, and it decreases (increases) consumer surplus iff $b>3.2(b<3.2)$; $b)$ if $b=1$, then a quality standard is always welfare decreasing, and it decreases (increases) consumer surplus iff $\alpha \lesssim 0.27(\alpha \gtrsim 0.27)$; c) if $b=\left(\frac{\alpha}{1-\alpha}\right)^{2}$ then for $\alpha \lesssim 0.215$ a quality standard raises both welfare and consumer surplus.

The previous result shows that, depending on the parameter values, a QS might decrease both welfare and consumer surplus, increase them both, or harm welfare while increasing consumer surplus. In contrast to previous studies of QS's in imperfectly competitive markets (Ronnen, 1991; Crampes and Hollander, 1995), Corollary 2 shows that even though the intervention intensifies price competition in oligopoly, it might harm consumers and total welfare. The undesired effects of intervention in this study stem from the existence of a critical mass of 
consumers whose valuation of the incremental quality imposed by the QS does not cover its cost. $^{19}$

Figure 2 presents expected welfare and consumer surplus in the symmetric unregulated equilibrium and under a QS: for fixed $\alpha$ and $\theta_{i}, c$ ranges from 8 to 9.7 such that $b\left(=\left(\theta_{1}-\theta_{3}+\right.\right.$ $\left.c) /\left(\theta_{4}-\theta_{2}-c\right)\right)$ ranges from 0 to 0.75 .

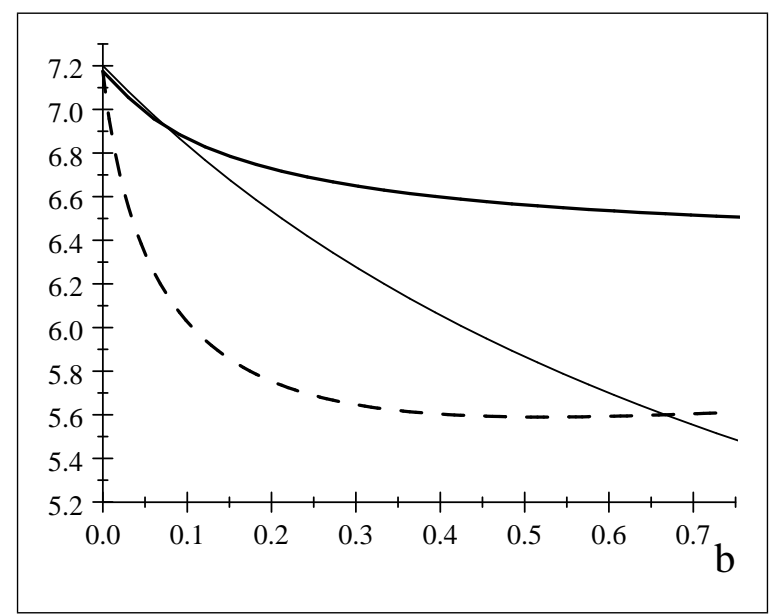

Figure 2: Expected welfare (thick line) and consumer surplus (dashed line) in the symmetric equilibrium. Welfare and consumer surplus (thin line) under a MQS. ( $N=2, \alpha=.2, \theta_{1}=6$,

$$
\left.\theta_{2}=8, \theta_{3}=14, \theta_{4}=20\right)
$$

Corollary 2 part c) shows that a QS is beneficial for the consumers and the society when there are few high-end consumers ( $\alpha$ small) and the relative efficiency gain of quality match to the low-end consumers (captured by $b=\left(\theta_{1}-\theta_{3}+c\right) /\left(\theta_{4}-\theta_{2}-c\right)$ ) is low. When $\alpha$ is small, the probability that all firms choose a low-quality is higher, and the intervention is more likely to make a difference to the high-end consumers. But, if $b$ is also low, a QS raises both consumer surplus and welfare. This is the case in Figure 2 where $\alpha=0.2$ for low enough $b$ 's. In this region, the positive effect of a QS on price competition offsets its negative effect on product diversity. In contrast, when there are many high-end consumers ( $\alpha$ large), $p_{2}$ (the best high-quality deal) is close to $c$ and $P$ (the probability of choosing a low-quality) is close to 0 , so that there is less scope for intervention.

For intermediate values of $b$ the intervention benefits consumers, but harms total welfare: in this region, the price effect is strong enough to offset the lack of product diversity, but the society is harmed by the quality mismatches. Finally for higher values of $b$, a QS harms both consumers and welfare: the relative net value of quality to the low-end consumers is high, and the negative impact of reduced variety dominates.

The analysis in this section shows that the impact of consumer protection in the form of QS stems from a trade-off between increasing competition and catering to consumers with different tastes for quality. Although the intervention increases competition, it also harms consumers

\footnotetext{
${ }^{19}$ Appendix B focuses on the uncovered market equilibrium and shows that a QS might still decrease welfare and consumer surplus, even when it improves consumers' participation in the market. (See Example 3.)
} 
when they place low value on quality. ${ }^{20}$ Understanding the undesired effects of QS is particularly important as recent evidence on consumers' inattention to fine print terms or shrouded price attributes might make consumer protection policy more appealing. If randomization on quality and prices is driven only by inattention (as in Armstrong and Chen, 2009), a QS is obviously beneficial. But, my analysis shows that similar market outcomes might stem from heterogeneity in consumers' tastes for quality. As the presence of few inattentive high-end consumers would not alter qualitatively the equilibrium strategies, with heterogeneous preferences, the effect of a QS meant to protect the inattentives is no longer clear-cut. As a QS forces low-end consumers to purchase an inefficiently high-quality product, it might actually harm consumers and welfare overall. $^{21}$

\section{Conclusions}

In professional service markets and in some consumer good markets, packaging, labelling, endorsements, or maintenance service terms can be used to offer better value to buyers. As quality improvements can be made in the short-run and are unlikely to be observed by rivals prior to product market interaction, these situations call for a model of simultaneous price and quality competition. This paper proposed an oligopoly model where ex-ante identical sellers compete in the provision of a product by simultaneously submitting price-quality bids. Each firm chooses one of two quality levels. The consumers have heterogeneous tastes for quality: it is efficient for some consumers to buy a high-quality, while for others is efficient to buy a low-quality. In the symmetric equilibrium firms use mixed strategies that randomize both price and quality, and obtain strictly positive profits.

The analysis of consumer protection in the form of quality standards in this setting captures (undesired) effects neglected by previous models of imperfect competition. The intervention increases price competition, but reduces product diversity.

\section{Appendix}

Proof of Lemma 1. a) If all firms choose high (or, low) quality, they compete a la Bertrand and make zero profits. Then, a unilateral deviation to a low (or, high) quality and price $p$ is profitable as it generates strictly positive profits equal to $(1-\alpha) \varepsilon$ (or, $\alpha(\varepsilon-c))$ whenever $0<p<c-\left(\theta_{3}-\theta_{1}\right)$ (or, $\left.c<p<\theta_{4}-\theta_{2}\right)$. Hence, there is no symmetric pure strategy equilibrium.

\footnotetext{
${ }^{20}$ Under perfect competition and informational asymmetries, Leland (1979) derives conditions under which QS increases welfare, but warns that "when entry is restricted in this manner detrimental side effects may occur." While the negative impact of intervention in his setting is the same as here, the positive effect is different as it stems from correcting the "lemons problem".

${ }^{21}$ Armstrong (2008, pp. 146-7) introduces inattention (some consumers prefer a high quality, but do not pay attention to quality) in the perfectly competitive version of this model and shows that a QS meant to protect the inattentive, might be beneficial or not depending on the parameter values. (In his perfectly competitive model, a QS is always harmful if there is no inattention. In contrast, under imperfect competition, QS do have a positive price effect.)
} 
b) If at least two firms offer a low-quality and at least two firms offer a high-quality, all firms compete a la Bertrand, make zero profits and there is no profitable unilateral deviation. In this equilibrium, all low-end consumers buy a low-quality at $p=0$ and all high-end consumers buy a high-quality at $p=c$.

\subsection{Appendix A: Covered Market Equilibrium}

\section{Conditions for the Existence of a Symmetric Covered Market Equilibrium}

For expositional simplicity, the main text assumes that (2) holds. This is a sufficient condition for the market to be covered in the symmetric equilibrium. Let us now derive (2) and present a more complex necessary condition for an arbitrary number of firms.

First note that the market is covered in the symmetric equilibrium if $p_{4} \leq \theta_{3}$, where $p_{4}$ is the upper bound of the support of the equilibrium pricing cdf. (Clearly, if $p_{4}>\theta_{3}$ there is a positive probability that low-end consumers are excluded from the market. This happens if all firm offer high-quality products at prices higher than low-end consumers' valuation of the high-quality product, $\theta_{3}$.) By (3) and (6),

$$
p_{4}=\left(\theta_{4}-\theta_{2}-c\right) \frac{\alpha}{1-\alpha} P^{N-1}+\theta_{4}-\theta_{2}
$$

Using the fact that $P<1$ (see 9 ), the requirement that $p_{4} \leq \theta_{3}$ leads to the sufficient condition $(2)$ :

$$
\alpha \leq \frac{\theta_{2}+\theta_{3}-\theta_{4}}{\theta_{3}-c}
$$

To obtain a necessary condition for the market to be covered in the symmetric equilibrium for an arbitrary number of firms, note that $P(N)$ is decreasing (see (9)), so that $p_{4}(N)$ is decreasing. It follows that $p_{4}(N) \leq p_{4}(2)$. Using $(15), p_{4}(2)=\left(\theta_{4}-\theta_{2}-c\right) \frac{\alpha}{1-\alpha} P(2)+\theta_{4}-\theta_{2}$, where $P(2)$ follows from (9):

$$
P(2)=\frac{b(1-\alpha)^{2}(2-\alpha)+\alpha^{2}(1-\alpha)-\sqrt{\left[b(1-\alpha)^{2}(2-\alpha)+\alpha^{2}(1-\alpha)\right]^{2}-4 b(1-\alpha)^{2}\left[b(1-\alpha)^{3}-\alpha^{3}\right]}}{2\left[b(1-\alpha)^{3}-\alpha^{3}\right]},
$$

where $b=\left(\theta_{1}-\theta_{3}+c\right) /\left(\theta_{4}-\theta_{2}-c\right)$. Then, $p_{4} \leq \theta_{3}$ for any $N \geq 2$ iff

$$
\frac{b(1-\alpha)(2-\alpha) \alpha+\alpha^{3}-\alpha \sqrt{\left[b(1-\alpha)(2-\alpha)+\alpha^{2}\right]^{2}-4 b\left[b(1-\alpha)^{3}-\alpha^{3}\right]}}{2\left[b(1-\alpha)^{3}-\alpha^{3}\right]} \leq \frac{\theta_{3}-\theta_{4}+\theta_{2}}{\theta_{4}-\theta_{2}-c}
$$

Proof of Proposition 1. For $F(p)$ defined by (10) and (11) to be a well-defined cdf, it has to be continuous and increasing on $S$. Let us first consider prices in $\left[p_{0}, p_{1}\right]$. By $(10), F$ is increasing in $p$. I show in continuation that $F\left(p_{0}\right)=0$. Notice that $(10)$ evaluated at $p_{0}$ gives

$$
p_{0}\left[(1-\alpha)\left(1-F\left(p_{0}\right)\right)^{N-1}+\alpha\left(P-F\left(p_{0}\right)\right)^{N-1}\right]=p_{1}(1-\alpha)(1-P)^{N-1}
$$

and using (6) and (8) it becomes

$$
\left(\frac{1-\alpha}{\alpha}\right)^{2} \frac{\theta_{1}-\theta_{3}+c}{\theta_{4}-\theta_{2}-c}\left[\frac{\alpha+(1-\alpha)(1-P)^{N-1}}{(1-\alpha)\left(1-F\left(p_{0}\right)\right)^{N-1}+\alpha\left(P-F\left(p_{0}\right)\right)^{N-1}}\right]=\left(\frac{P}{1-P}\right)^{N-1}
$$


But from (9) and (16), it follows that $F\left(p_{0}\right)=0$.

Let us consider prices in $\left[p_{2}, \theta_{3}\right] \cap\left[p_{2}, p_{4}\right]$. By (11), $F$ is increasing in $p$. I show in continuation that $F\left(p_{2}\right)=P$. Notice that (11) evaluated at $p_{2}$ gives

$$
\begin{gathered}
\left(p_{2}-c\right)\left[\alpha\left(P+1-F\left(p_{2}\right)\right)^{N-1}+(1-\alpha)\left(1-F\left(p_{2}\right)\right)^{N-1}\right]=\left(p_{0}+\theta_{4}-\theta_{2}-c\right) \alpha P^{N-1} \Leftrightarrow \\
\left(p_{1}+\theta_{3}-\theta_{1}-c\right)\left[\alpha\left(P+1-F\left(p_{2}\right)\right)^{N-1}+(1-\alpha)\left(1-F\left(p_{2}\right)\right)^{N-1}\right]=\left(p_{0}+\theta_{4}-\theta_{2}-c\right) \alpha P^{N-1}
\end{gathered}
$$

and using (6) and (8) it becomes

$$
\left(\frac{1-\alpha}{\alpha}\right)^{2} \frac{\theta_{1}-\theta_{3}+c}{\theta_{4}-\theta_{2}-c}\left[\frac{\alpha\left(P+1-F\left(p_{2}\right)\right)^{N-1}+(1-\alpha)\left(1-F\left(p_{2}\right)\right)^{N-1}}{1-\alpha+\alpha P^{N-1}}\right]=\left(\frac{P}{1-P}\right)^{N-1} .
$$

But from (9) and (17), it follows that $F\left(p_{2}\right)=P=F\left(p_{1}\right)$. In addition, notice that if $p_{4}=$ $p_{0}+\theta_{4}-\theta_{2} \in\left[p_{2}, \theta_{3}\right]$ then (11) evaluated at $p_{4}$ gives

$$
\left(p_{4}-c\right)\left[\alpha\left(P+1-F\left(p_{4}\right)\right)^{N-1}+(1-\alpha)\left(1-F\left(p_{4}\right)\right)^{N-1}\right]=\left(p_{4}-c\right) \alpha P^{N-1}
$$

and it follows that $F\left(p_{4}\right)=1$.

The boundary price $p_{1}$ should not exceed $\theta_{1}$. If $p_{4} \leq \theta_{3}$, from (5) and (7), it follows that

$$
p_{1}=\theta_{1}-\theta_{3}+c+\left(p_{0}+\theta_{4}-\theta_{2}-c\right) \frac{\alpha P^{N-1}}{\alpha+(1-\alpha)(1-P)^{N-1}} \leq \theta_{1}-\theta_{3}+p_{4} \leq \theta_{1} .
$$

For the strategies presented in Proposition 1 to be indeed an equilibrium, there should be no profitable unilateral deviation. The relevant deviations to be considered in this case are the following: i. offer a low-quality at $p \in\left(p_{1}, \theta_{1}\right]$; ii. offer a high-quality at $p \in\left[c, p_{2}\right]$; and iii. offer a high-quality at $p \in\left(p_{4}, \theta_{4}\right]$.

Notice that deviations with a high-quality on $\left[p_{0}, c\right]$ are not profitable because the price is below marginal cost and deviations with a low-quality in $\left(\theta_{2}, \theta_{4}\right]$ are not profitable because the price exceeds the willingness to pay for low-quality. Notice that deviations with a low-quality to some price $p \in\left(\theta_{1}, \theta_{2}\right) \cap\left(p_{1}, \theta_{2}\right)$ are not profitable: Low-end consumers cannot afford the low-quality. High-end consumers buy only if a high-quality is not offered at this price (i.e., $F\left(\theta_{2}\right) \leq F\left(p_{2}\right)$ ). Then, they purchase at $p$ with probability $\left(P-F(p)+1-F\left(p+\theta_{4}-\theta_{2}\right)\right)^{N-1}=0$. The last equality follows from the fact that, in this range, $p+\theta_{4}-\theta_{2}>p_{0}+\theta_{4}-\theta_{2}=p_{4}$ so that $F\left(p+\theta_{4}-\theta_{2}\right)=1$ and $F(p)=P$.

i. The deviator offers a low-quality at $p \in\left(p_{1}, \theta_{1}\right]$. low-end consumers buy at $p$ only if all other firms price above $\theta_{3}-\theta_{1}+p$. high-end consumers buy at $p$ with probability $(P-F(p)+1-$ $\left.F\left(p+\theta_{4}-\theta_{2}\right)\right)^{N-1}=0$. Then, deviator's profit is

$$
\pi_{D}(p)=p(1-\alpha)\left(1-F\left(p+\theta_{3}-\theta_{1}\right)\right)^{N-1} .
$$

As $p \in\left(p_{1}, \theta_{1}\right]$, notice that $p+\theta-\theta_{L} \in\left(p_{1}+\theta_{3}-\theta_{1}, \theta_{3}\right]=\left(p_{2}, \theta_{3}\right]$. Then $F\left(p+\theta_{3}-\theta_{1}\right)$ is defined by

$$
\left(p+\theta_{3}-\theta_{1}-c\right)\left[\alpha\left(1-F\left(p+\theta_{3}-\theta_{1}\right)+P\right)^{N-1}+(1-\alpha)\left(1-F\left(p+\theta_{3}-\theta_{1}\right)\right)^{N-1}\right]=\pi_{E} .
$$


Notice that, by continuity, $\pi_{D}\left(p_{1}\right)=p_{1}(1-\alpha)\left(1-F\left(p_{2}\right)\right)^{N-1}=p_{1}(1-\alpha)(1-P)^{N-1}=\pi_{E}$. Using (18), deviator's price and profits are given respectively by

$$
\begin{gathered}
p=c+\theta_{1}-\theta_{3}+\frac{\pi_{E}}{\left[\alpha\left(1-F\left(p+\theta_{3}-\theta_{1}\right)+P\right)^{N-1}+(1-\alpha)\left(1-F\left(p+\theta_{3}-\theta_{1}\right)\right)^{N-1}\right]} \text { and } \\
\pi_{D}(F)=\left\{c+\theta_{1}-\theta_{3}+\frac{\pi_{E}}{\left[\alpha(1-F+P)^{N-1}+(1-\alpha)(1-F)^{N-1}\right]}\right\}(1-\alpha)(1-F)^{N-1} .
\end{gathered}
$$

For $\theta_{3}-c<\theta_{1}, \frac{\partial \pi_{D}(F)}{\partial F}<0$ such that $\pi_{D}(p) \leq \pi_{D}\left(p_{1}\right)=\pi_{E}$. Consequently, this is not a profitable deviation.

ii. The deviator offers a high-quality at $p \in\left[c, p_{2}\right)$. Then, his expected profit is

$$
\pi_{D}(p)=(p-c)\left[\alpha+(1-\alpha)\left(1-F\left(p+\theta_{1}-\theta_{3}\right)\right)^{N-1}\right] .
$$

Clearly, all high-end consumers buy at $p$. low-end consumers buy only if all other firms price above $p+\theta_{1}-\theta_{3}$. As $p \in\left[c, p_{2}\right),\left(p+\theta_{1}-\theta_{3}\right) \in\left[c+\theta_{1}-\theta_{3}, p_{1}\right)$.

First let us consider deviations to $p$ such that $p+\theta_{1}-\theta_{3} \in\left[p_{0}, p_{1}\right)$. Then, $F\left(p+\theta_{1}-\theta_{3}\right)$ is defined by

$$
\left(p+\theta_{1}-\theta_{3}\right)\left[(1-\alpha)\left(1-F\left(p+\theta_{1}-\theta_{3}\right)\right)^{N-1}+\alpha\left(P-F\left(p+\theta_{1}-\theta_{3}\right)\right)^{N-1}\right]=p_{1}(1-\alpha)(1-P)^{N-1} .
$$

By (19), deviator's price and its profit are respectively:

$$
\begin{gathered}
p=\theta_{3}-\theta_{1}+\frac{p_{1}(1-\alpha)(1-P)^{N-1}}{(1-\alpha)(1-F)^{N-1}+\alpha(P-F)^{N-1}}>c \text { and } \\
\pi_{D}(F)=\left\{\theta_{3}-\theta_{1}-c+\frac{p_{1}(1-\alpha)(1-P)^{N-1}}{(1-\alpha)(1-F)^{N-1}+\alpha(P-F)^{N-1}}\right\}\left[\alpha+(1-\alpha)(1-F)^{N-1}\right] .
\end{gathered}
$$

It can be shown that $\frac{\partial \pi_{D}(F)}{\partial F}>0$ (recall that $\theta_{3}-\theta_{1}-c<0$ ), and then for all $p \in\left[p_{0}, p_{1}\right.$ ), $\pi_{D}(p) \leq \pi_{D}\left(p_{2}\right)$. But, $\pi_{D}\left(p_{2}\right)=\left(p_{2}-c\right)\left[\alpha+(1-\alpha)(1-P)^{N-1}\right]=\pi_{E}$. Consequently, this is not a profitable deviation.

If $c+\theta_{1}-\theta_{3}<p_{0}$ for some $N$, then for any $p \in\left[c+\theta_{1}-\theta_{3}, p_{0}\right]$, it holds that $F\left(p+\theta_{1}-\theta_{3}\right)=0$. It follows that $\frac{\partial \pi_{D}(p)}{\partial p}>0$ and $\pi_{D}(p) \leq \pi_{D}\left(p_{0}\right) \leq \pi_{E}$ as the previous argument applies. (Notice however that as $N \rightarrow \infty, p_{0} \rightarrow 0$, and $c+\theta_{1}-\theta_{3}>0$.)

iii. The deviator offers a high-quality at $p \in\left(p_{4}, \theta_{4}\right]$. Low-end consumers do not buy here (they strictly prefer a low quality, or a high quality at a lower price), and high-end consumers buy only if deviator's deal is the best available. For deviations with $p \in\left[p_{4}, p_{1}+\theta_{4}-\theta_{2}\right]$, deviator's profit is

$$
\pi_{D}(p)=(p-c) \alpha\left(P-F\left(p+\theta_{2}-\theta_{4}\right)\right)^{N-1} .
$$

For $p \in\left(p_{4}, p_{1}+\theta_{4}-\theta_{2}\right], p+\theta_{2}-\theta_{4} \in\left(p_{0}, p_{1}\right]$ and $F\left(p+\theta_{2}-\theta_{4}\right)$ is defined by

$$
\left(p+\theta_{2}-\theta_{4}\right)\left[(1-\alpha)\left(1-F\left(p+\theta_{2}-\theta_{4}\right)\right)^{N-1}+\alpha\left(P-F\left(p+\theta_{2}-\theta_{4}\right)\right)^{N-1}\right]=\pi_{E} .
$$

By (24), deviator's price and its profit can be written respectively as:

$$
\begin{gathered}
p=\theta_{4}-\theta_{2}+c+\frac{\pi_{E}}{(1-\alpha)(1-F)^{N-1}+\alpha(P-F)^{N-1}} \text { and } \\
\pi_{D}(F)=\left\{\theta_{4}-\theta_{2}-c+\frac{\pi_{E}}{(1-\alpha)(1-F)^{N-1}+\alpha(P-F)^{N-1}}\right\} \alpha(P-F)^{N-1} .
\end{gathered}
$$


It can be shown that $\frac{\partial \pi_{D}(F)}{\partial F}<0$ (recall that $\theta_{4}-\theta_{2}-c>0$ ), and then in the relevant range $\pi_{D}(p) \leq \pi_{D}\left(p_{4}\right)$. Notice that $\pi_{D}\left(p_{4}\right)=\left(p_{0}+\theta_{4}-\theta_{2}-c\right) \alpha P^{N-1}=\pi_{E}$. Hence, there is no gain from such deviation. For deviations with $p \in\left(p_{1}+\theta_{4}-\theta_{2}, \theta_{4}\right]$, neither low-end nor high-end consumers purchase, so clearly there is no gain from such deviation.

Finally, notice that, as the deviations above are not profitable, firms cannot gain from mixing on quality either.

Proof of Corollary 2. a) Let $\alpha=1 / 2$. Then, (9) becomes

$$
b\left(\frac{2-P}{1+P}\right)=\left(\frac{P}{1-P}\right) \Leftrightarrow P=\frac{1+3 b-\sqrt{1+b(14+b)}}{-2(1-b)} \text { for } b \neq 1 \text { and } P=1 / 2 \text { for } b=1 .
$$

It can be easily checked that $P \in(0,1)$ for $b \in(0, \infty)$ with $\lim _{b \rightarrow \infty} P=1$. For $N \geq 2$, a QS is welfare decreasing if

$$
\left(\theta_{4}-\theta_{2}-c\right) P^{2}<\left(\theta_{3}-\theta_{1}-c\right)\left[(1-P)^{2}-1\right] \Leftrightarrow P<\frac{2 b}{2 b+1},
$$

and is consumer surplus decreasing if

$$
\left(\theta_{4}-\theta_{2}-c\right) P[P+2(1+P)]<\left(c-\theta_{3}+\theta_{1}\right)\left[1-(1-P)^{2}\right] \Leftrightarrow P<\frac{2(b-1)}{3+b} .
$$

The result then follows.

b) Let $b=1$. Then, (9) becomes

$$
\begin{gathered}
\left(\frac{1-\alpha}{\alpha}\right)^{2}\left[\frac{\alpha+(1-\alpha)(1-P)}{(1-\alpha)+\alpha P}\right]=\left(\frac{P}{1-P}\right) \Leftrightarrow \\
P=\frac{(1-\alpha)\left[2(1-\alpha)^{2}+\alpha-\alpha \sqrt{(1-2 \alpha)^{2}+4}\right]}{2(1-2 \alpha)\left(1-\alpha+\alpha^{2}\right)} \text { if } \alpha \neq 1 / 2 \text { and } P=1 / 2 \text { if } \alpha=1 / 2 .
\end{gathered}
$$

It can be easily checked that $P \in(0,1)$ for $\alpha \in(0,1)$ with $\lim _{\alpha \rightarrow 0} P=1$ and $\lim _{\alpha \rightarrow 1} P=0$.

A QS is welfare decreasing whenever

$$
\alpha P^{2}<(1-\alpha)\left[1-(1-P)^{2}\right] \Leftrightarrow P<2(1-\alpha),
$$

which turns out to be true for all $\alpha$ 's.

A QS is consumer surplus decreasing if

$$
\alpha P\left[P+2\left(1+\frac{\alpha}{1-\alpha} P\right)\right]<(1-\alpha)\left[1-(1-P)^{2}\right] \Leftrightarrow P<\frac{2(1-2 \alpha)(1-\alpha)}{1-\alpha+\alpha^{2}} .
$$

This leads to the result.

c) Let $b=\left(\frac{\alpha}{1-\alpha}\right)^{2}$. Then, (9) becomes:

$$
\begin{gathered}
{\left[\frac{\alpha+(1-\alpha)(1-P)}{(1-\alpha)+\alpha P}\right]=\left(\frac{P}{1-P}\right) \Leftrightarrow} \\
P=\frac{2(1-\alpha)+\sqrt{5-4 \alpha(1-\alpha)}]}{2(1-2 \alpha)} \text { for } \alpha \neq 1 / 2 \text { and } P=1 / 2 \text { for } \alpha=1 / 2 .
\end{gathered}
$$

It can be easily checked that $P \in(0,1)$ for $\alpha \in(0,1)$ with $\lim _{\alpha \rightarrow 1} P=0$. First notice that if a QS raises welfare, then it also raises consumer surplus (see Proposition 2). A QS is welfare increasing whenever

$$
\left(\theta_{4}-\theta_{2}-c\right) \alpha P^{2}>\left(c-\theta_{3}+\theta_{1}\right)(1-\alpha)\left[1-(1-P)^{2}\right] \Leftrightarrow P>\frac{2 b(1-\alpha)}{\alpha+b(1-\alpha)} .
$$

The result then follows. 


\subsection{Appendix B: Uncovered Market Equilibrium}

In this part, I present the symmetric mixed strategy equilibrium in the uncovered market case. A sufficient condition for the market to be uncovered is $\theta_{4}-\theta_{2}>\theta_{3}$. In this case the support of the price cdf is $\left[p_{0}, p_{1}\right] \cup\left[p_{2}, \theta_{3}\right] \cup\left[p_{3}, p_{4}\right]$. Notice first that expressions (3)-(9) still apply. To pin down the equilibrium cdf's it is necessary to identify the boundary price $p_{3}$ and the probability to price below $\theta_{3}$, that is $F\left(\theta_{3}\right)<1$. These are implicitly defined by (5) together with:

$$
\begin{gathered}
\pi\left(\theta_{3}\right)=\left(\theta_{3}-c\right)\left[\alpha\left(P+1-F\left(\theta_{3}\right)\right)^{N-1}+(1-\alpha)\left(1-F\left(\theta_{3}\right)\right)^{N-1}\right] \text { and } \\
\pi\left(p_{3}\right)=\left(p_{3}-c\right) \alpha\left(P+1-F\left(\theta_{3}\right)\right)^{N-1} .
\end{gathered}
$$

low-end consumers purchase a high-quality at $\theta_{3}$ (which leaves them with zero net surplus) only if this is the lowest price in the market and they no longer purchase it at $p_{3}$ because their valuation of a high-quality is lower. high-end consumers obtain a higher net surplus from the high-quality sold at $\theta_{3}$ than from the best possible low-quality deal, that is $\theta_{4}-\theta_{3}>\theta_{2}-p_{0} \Leftrightarrow \theta_{4}-\theta_{2}+p_{0}>\theta_{3}$. Similarly, high-end consumers obtain a higher net surplus from the high-quality sold at $p_{3}$ than from the best possible low-quality deal, that is $\theta_{4}-p_{3}>\theta_{2}-p_{0} \Leftrightarrow \theta_{4}-\theta_{2}+p_{0}=p_{4}>p_{3}$. Hence, they buy at $\theta_{3}$ or at $p_{3}$ if all other firms offer a low-quality or charge a higher price.

Proposition 3 For $N \geq 2$ and $\theta_{4}-\theta_{2}>\theta_{3}$, there exists a symmetric mixed strategy equilibrium where firms randomize on prices and qualities. Firms choose prices with support $S=\left[p_{0}, p_{1}\right] \cup$ $\left[p_{2}, \theta_{3}\right] \cup\left[p_{3}, p_{4}\right]$. The boundary prices $p_{0}, p_{1}, p_{2}, p_{3}$ and $p_{4}$ are defined by (3), (6), (8) and (21). The atomless pricing cdf $F(p)$ is defined implicitly by

$$
\begin{gathered}
p\left[(1-\alpha)(1-F(p))^{N-1}+\alpha(P-F(p))^{N-1}\right]=p_{1}(1-\alpha)(1-P)^{N-1} \text { for } p_{0} \leq p \leq p_{1} ; \\
(p-c)\left[\alpha(P+1-F(p))^{N-1}+(1-\alpha)(1-F(p))^{N-1}\right]= \\
\left(p_{0}+\theta_{4}-\theta_{2}-c\right) \alpha P^{N-1} \text { for } p_{2} \leq p \leq \theta_{3} ; \text { and } \\
(p-c) \alpha(P+1-F(p))^{N-1}=\left(p_{0}+\theta_{4}-\theta_{2}-c\right) \alpha P^{N-1} \text { for } p_{3} \leq p \leq p_{4} .
\end{gathered}
$$

where $P=F\left(p_{1}\right)=F\left(p_{2}\right)$ is the probability of choosing a low-quality defined by (9) and $p_{3}$ is defined by (5) and (21). A low-quality is associated with prices in $\left[p_{0}, p_{1}\right]$ and a high-quality with prices in $\left[p_{2}, p_{4}\right]$.

Proof. As most of the arguments overlap with those presented in the proof of proposition 1, I focus here on the additional arguments required for the uncovered market case.

a) Pricing cdf analysis. Let us consider prices in $\left[p_{3}, p_{4}\right]$ which are assigned positive density if $p_{4}>\theta_{3}$. By (22), $F$ is increasing in $p$. I show in continuation that $F\left(p_{3}\right)=F\left(\theta_{3}\right)$. Notice first that from (21), the boundary price $p_{3}$ is given by

$$
p_{3}=c+\frac{\left(\theta_{3}-c\right)\left[\alpha\left(P+1-F\left(\theta_{3}\right)\right)^{N-1}+(1-\alpha)\left(1-F\left(\theta_{3}\right)\right)^{N-1}\right]}{\alpha\left(P+1-F\left(\theta_{3}\right)\right)^{N-1}} .
$$


If we evaluate $(22)$ at $p_{3}$ and substitute (23), then it becomes

$$
\begin{gathered}
\frac{\left(\theta_{3}-c\right)\left[\alpha\left(P+1-F\left(\theta_{3}\right)\right)^{N-1}+(1-\alpha)\left(1-F\left(\theta_{3}\right)\right)^{N-1}\right]}{\alpha\left(P+1-F\left(\theta_{3}\right)\right)^{N-1}} \alpha\left(P+1-F\left(p_{3}\right)\right)^{N-1}= \\
\left(p_{0}+\theta_{4}-\theta_{2}-c\right) \alpha P^{N-1} .
\end{gathered}
$$

But, as indifference between $\theta_{3}$ and $p_{4}$ requires

$$
\left(\theta_{3}-c\right)\left[\alpha\left(P+1-F\left(\theta_{3}\right)\right)^{N-1}+(1-\alpha)\left(1-F\left(\theta_{3}\right)\right)^{N-1}\right]=\left(p_{0}+\theta_{4}-\theta_{2}-c\right) \alpha P^{N-1}
$$

it follows that $F\left(p_{3}\right)=F\left(\theta_{3}\right)$.

b) Boundary prices. When $p_{4}>\theta_{3}$, from $(7)$ and $\pi\left(\theta_{3}\right)$ in (21), it follows that

$$
p_{1}=\theta_{1}-\theta_{3}+c+\left(\theta_{3}-c\right) \frac{\alpha\left(P+1-F\left(\theta_{3}\right)\right)^{N-1}+(1-\alpha)\left(1-F\left(\theta_{3}\right)\right)^{N-1}}{\alpha+(1-\alpha)(1-P)^{N-1}} \leq \theta_{1} .
$$

Also, using (5) and (21), it can also be shown that $p_{3} \in\left(\theta_{3}, p_{4}\right)$.

c) Deviations. Two additional deviations need to be considered in this case. Note that they replace iii) in the Proof of Proposition 1. First, suppose that the deviator offers a high-quality at $p \in\left(\theta_{3}, p_{3}\right)$. low-end consumers do not buy here, so deviator's profit is

$$
\pi_{D}(p)=(p-c) \alpha\left(P+1-F\left(\theta_{3}\right)\right)^{N-1}<\left(p_{3}-c\right) \alpha\left(P+1-F\left(\theta_{3}\right)\right)^{N-1}=\pi_{E} .
$$

Such deviation is not profitable. Finally, suppose that the deviator offers a high-quality at $p \in\left(p_{4}, \theta_{4}\right)$. low-end consumers do not buy here, so deviator's profit is

$$
\pi_{D}(p)=(p-c) \alpha\left(P-F\left(p+\theta_{2}-\theta_{4}\right)\right)^{N-1} .
$$

When $p \in\left(p_{4}, \theta_{4}\right)$, then $p+\theta_{2}-\theta_{4} \in\left(p_{0}, \theta_{2}\right)$ so that $F\left(p+\theta_{2}-\theta_{4}\right)$ is defined by

$$
\left(p+\theta_{2}-\theta_{4}\right)\left[(1-\alpha)\left(1-F\left(p+\theta_{2}-\theta_{4}\right)\right)^{N-1}+\alpha\left(P-F\left(p+\theta_{2}-\theta_{4}\right)\right)^{N-1}\right]=\pi_{E} .
$$

By (24), deviator's price and its profit can be written respectively as:

$$
\begin{gathered}
p=\theta_{4}-\theta_{2}+c+\frac{\pi_{E}}{(1-\alpha)(1-F)^{N-1}+\alpha(P-F)^{N-1}} \text { and } \\
\pi_{D}(F)=\left\{\theta_{4}-\theta_{2}-c+\frac{\pi_{E}}{(1-\alpha)(1-F)^{N-1}+\alpha(P-F)^{N-1}}\right\} \alpha(P-F)^{N-1} .
\end{gathered}
$$

It can be shown that $\frac{\partial \pi_{D}(F)}{\partial F}<0$ (recall that $\theta_{4}-\theta_{2}-c>0$ ), and then in the relevant range $\pi_{D}(p) \leq \pi_{D}\left(p_{4}\right)$. Notice that $\pi_{D}\left(p_{4}\right)=\left(p_{0}+\theta_{4}-\theta_{2}-c\right) \alpha P^{N-1}=\pi_{E}$. Hence, there is no gain from such deviation, either.

The following example illustrates the type of mixed strategy equilibrium presented in Proposition 3 .

Example 2 Let $N=2, \alpha=.5, \theta_{1}=6, \theta_{2}=7, c=10, \theta_{3}=14$ and $\theta_{4}=23$. Using the results in Proposition 2, at equilibrium, $p_{0}=1.82, p_{1}=3.39, p_{2}=11.39, p_{3}=15.29, p_{4}=17.82$, $P=.30$ and $F\left(\theta_{3}\right)=.86$. The price $c d f$ is

$$
F(p)=\left\{\begin{array}{c}
.65-\frac{1.183}{p} \text { for } p \in[1.82,3.39] \\
1.15-\frac{1.183}{p-10} \text { for } p \in[11.39,14] \\
1.3-\frac{2.366}{p-10)} \text { for } p \in[15.29,17.82]
\end{array} .\right.
$$


The equilibrium profit is 1.183. Consumer surplus is 6.33 and total welfare is 8.69. Figure 3 illustrates the mixed strategy equilibrium in this case.

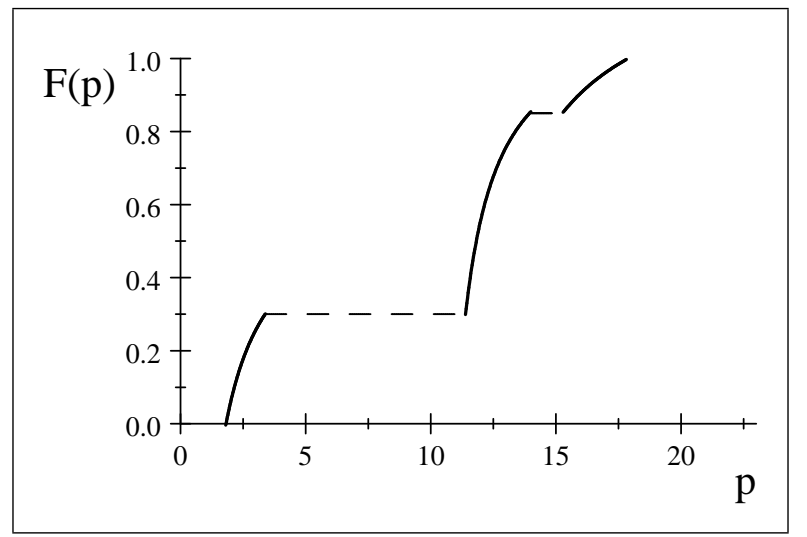

Figure 3: The price cdf in Example 2

As before, expected profit of a firm is given by $\pi_{E}=\left(\theta_{4}-\theta_{2}-c\right)\left(1+\frac{\alpha}{1-\alpha} P^{N-1}\right) \alpha P^{N-1}$. If $p_{4}>\theta_{3}$, a minimum quality standard is welfare decreasing whenever

$$
\left(\theta_{4}-\theta_{2}-c\right) \alpha P^{N}+\left(\theta_{3}-c\right)(1-\alpha)\left(1-F\left(\theta_{3}\right)\right)^{N}<\left(\theta_{3}-\theta_{1}-c\right)(1-\alpha)\left[(1-P)^{N}-1\right] .
$$

In the equilibrium presented in Proposition 3, high-end consumers buy a high-quality if at least one firm supplies it (which happens with probability $1-P^{N}$ ), and low-end consumers buy a low-quality if at least one firm supplies it (which happens with probability $1-(1-P)^{N}$ ). Then, only if all firms offer a low-quality, high-end consumers buy a low-quality. And, low-end consumers buy a high-quality only if all firms offer a price in the interval $\left[p_{2}, \theta_{3}\right]$. Then, welfare is given by:

$\left(\theta_{4}-c\right) \alpha\left(1-P^{N}\right)+\theta_{2} \alpha P^{N}+\theta_{1}(1-\alpha)\left[1-(1-P)^{N}\right]+\left(\theta_{3}-c\right)(1-\alpha)\left[(1-P)^{N}-\left(1-F\left(\theta_{3}\right)\right)^{N}\right]$.

Consumer surplus equals total welfare minus aggregate profits.

Welfare and consumer surplus under a relevant QS are given by (14). When $p_{4}>\theta_{3}$, a QS might decrease both consumer surplus and welfare (see Example 3); raise both consumer surplus and welfare (see Example 4); or decrease welfare and raise consumer surplus (see Example 2 and notice that welfare and consumer surplus under a QS is 8.5).

Example 3 Let $N=2, \alpha=.1, \theta_{1}=7, \theta_{2}=8, c=10, \theta_{3}=14$ and $\theta_{4}=23$. Under $a Q S$, welfare and consumer surplus equal $W_{M Q S}=C S_{M Q S}=4.9$, while at the symmetric equilibrium the free market creates total welfare $W=7.16$ and consumer surplus $C S=6.17$. Then, a $Q S$ reduces total welfare by 2.26 and consumer surplus by 1.27 . (In this case, $p_{4}=15.5>\theta_{3}=14$.)

Example 4 Let $\alpha=.5, \theta_{1}=6, \theta_{2}=7, c=10, \theta_{3}=14$ and $\theta_{4}=30$. Under a $Q S$, welfare and consumer surplus equal $W_{M Q S}=C S_{M Q S}=12$, while at the symmetric equilibrium the free market creates total welfare $W=11.96$ and consumer surplus of $C S=9.02$. Then, a $Q S$ raises total welfare by .04 and consumer surplus by 2.98 . 


\section{References}

Armstrong, M. "Interactions between Competition and Consumer Policy." Competition Policy International, Vol. 4 (2008), pp. 96-147.

Armstrong, M. and Chen, Y. "Inattentive Consumers and Product Quality." Journal of the European Economic Association, Vol. 7(2-3) (2009), pp. 411-422.

Baye, M., Morgan, J. and Scholten, P. "Information, Search, and Price Dispersion." Handbook on Economics and Information Systems, edited by T. Hendershott, Elsevier (2006).

Besanko, D., Donnenfeld, S. and White, L.J. "The Multiproduct Firm, Quality Choice, and Regulation." Journal of Industrial Economics, Vol. 36(4) (1988), pp. 411-29.

Che, Y.-K. and Choi, A. H. "Shrink-Wraps: Who Should Bear the Cost of Communicating Mass-Market Contract Terms?." (2009) mimeo.

Crampes, J. and Hollander, A. "Duopoly and Quality Standards." European Economic Review, Vol. 39 (1995), pp.71-82.

Leland, H.E. "Quacks, Lemons, and Licensing: A Theory of Minimum Quality Standards." Journal of Political Economy, Vol. 87 (1979), pp. 1328-1346.

Ronnen, U. "Minimum Quality Standards, Fixed Costs, and Competition." Rand Journal of Economics, Vol. 22(4) (1991), pp. 490-504.

Rosenthal, R. "A model in which an increase in the number of sellers leads to a higher price." Econometrica, Vol. 48 (1980), pp. 1575-1579.

Shapiro, C. "Premiums for high-quality products as returns to reputations." Quarterly Journal of Economics, Vol. 98 (1983), pp. 659-680.

Valletti, T. "Minimum Quality Standards under Cournot Competition." Journal of Regulatory Economics, Vol. 18(3) (2000), pp. 235-45.

Varian, H. "A model of sales." American Economic Review, Vol. 70 (1980), pp. 651-659. 